\title{
Produção de materiais didáticos e planejamento de aula em equipe: a experiência de formação de professores do NUPPLES/UERJ
}

Didactic materials development and collaborative class planning: on teachers' training experience of NUPPLES/UERJ

Alexandre do Amaral Ribeiro, Doutor em Linguística, UERJ, alexandreribeiro@nupples.pro.br

Débora Marinho Guerra, Mestranda em Língua Portuguesa, UERJ, debbieguerra@globo.com

\section{Resumo}

A elaboração de materiais didáticos é um caminho para a formação de professores. Este artigo busca, portanto, identificar e analisar desafios de professores de PL2E em formação no NUPPLES/UERJ para elaborar materiais para suas aulas de forma integrada com seus planos de aula contribuindo para o desenvolvimento de competências didático-pedagógicas.

Palavras-chave: materiais didáticos, formação de professores, competências didático-pedagógicas.

\section{Abstract}

The preparation of didactic materials is an important stage in teacher education. This article seeks to identify and analyze teachers' challenges to develop materials that are coherent with their lesson plans that are collaboratively proposed. It also reflects on the implications of this process for the teaching skills development.

Keywords: didactic materials, teacher's training, didactic and pedagogical skills 


\section{Introdução}

A formação de professores implica a promoção de diferentes ações em prol do desenvolvimento de competências didático-pedagógicas que Ihes assegurem boa qualidade de atuação e autonomia profissional. Trata-se de um processo que demanda treinamento e construção compartilhada de saberes docentes em um constante esforço de reflexão que alia teoria e prática.

Dentre as várias experiências que compõem o universo de formação docente, encontram-se a de elaborar e a de operacionalizar planos de aula, incluindo-se nessa tarefa a de propor e a de produzir materiais didáticos adequados ao perfil da turma e às situações de sala de aula. Nesse sentido, cada plano elaborado e os materiais a ele associados transformam-se em oportunidades de discussão teóricoprática cujo conteúdo amplia as possibilidades de formação profissional.

É nesse contexto que o presente artigo problematiza o processo de produção de materiais didáticos, especificamente, os relacionados à área de Português como Segunda Língua e Língua Estrangeira (doravante PL2E), uma vez que se insere no processo de formação de alunos estrangeiros e formação de professores de PL2E. Toma, portanto, como objeto de discussão o material didático e sua produção como indicadores de pontos a serem considerados e trabalhados na formação de professores.

Interessa identificar e analisar os desafios de professores em formação para o desempenho coerente e integrado das tarefas de planejar aulas e de produzir materiais didáticos. Em termos metodológicos, tais objetivos irão constituir a base dos procedimentos e do estabelecimento de critérios de análise, uma vez que as dificuldades teórico-metodológicas da realização de práticas docentes em período de formação tornam-se dados que nortearão as decisões relativas à melhoria da qualidade do material produzido de modo articulado com os resultados do seu processo de formação.

No que concerne às abordagens teóricas que dão respaldo à coleta e à análise dos dados, buscam-se as contribuições da Linguística Aplicada à Didática do Ensino de Línguas, da Pragmática Linguística e da Formação de Professores. Todas concorrem para pensar as discussões sobre a produção de Materiais Didáticos e suas implicações para a prática docente, considerando-se ainda o contexto da "Educação à Distância". Ainda que este não esteja diretamente ligado às práticas descritas neste artigo, há que se considerar suas contribuições para repensar estratégias didáticas de um modo geral, sobretudo no que se refere ao planejamento de aula em equipe.

Não é raro encontrar profissionais que depositam no material didático, incluindo-se aí o livro didático, toda a responsabilidade por sua ação pedagógica, limitando-se a "seguir o livro didático" sem qualquer autonomia pedagógica. Essa realidade não parece ser fruto de uma boa formação docente em que, entre outras competências e habilidades, o professor será capaz de tomar decisões sobre a 
produção e também sobre as formas de utilização de materiais didáticos já existentes no mercado para fins de atingir objetivos no âmbito do ensinoaprendizagem. Nesse sentido, o professor precisa ter bom domínio do conteúdo de suas aulas e plena consciência das possibilidades de apresentá-lo ao público-alvo de forma significativa e coerente para as tarefas internas e externas à aula.

\section{Planejamento de aulas e produção de material didático: um trabalho em equipe}

O trabalho de formação inicial de professores de PL2E da Universidade do Estado do Rio de Janeiro (UERJ) é realizado pelo Núcleo de Pesquisa e de Ensino de Português Língua Estrangeira/Segunda Língua (NUPPLES). Trata-se de um Projeto de Pesquisa e de Extensão que integra graduandos e pós-graduandos em Língua Portuguesa. Embora cada membro da equipe tenha responsabilidades específicas, todos colaboram para a execução de todas as atividades. Dessa forma, os estagiários de Iniciação à Docência, responsáveis por ministrar as aulas do curso de extensão de português para estrangeiros não atuam isoladamente.

Todo o processo de formação docente dos estagiários passa pelo acompanhamento de pós-graduandos e, obrigatoriamente, da supervisão do professor-coordenador, promovendo-se regularmente discussões, estudos e revisões de materiais didáticos cuja elaboração exige reflexão sobre conteúdo e aplicabilidade em aula, pois

(...) pouco adianta existirem materiais didáticos de excelente qualidade se os professores não desenvolverem competências e habilidades didático-pedagógicas que, postas em ação juntamente com seus conhecimentos técnicos, criam as condições necessárias ao sucesso do processo de ensino-aprendizagem. (RIBEIRO, 2015, p. 73).

Dessa forma, dentre as atividades de formação encontram-se as de propor planos de aulas do tipo roteiro de atividades, adequados ao perfil da turma e ao plano de curso. A descrição e avaliação da aula são efetivamente entendidas como dados para discussão e tomada de decisão. Além de propor novos materiais didáticos, os estagiários podem rever atividades previamente prontas, redimensionando-as para os propósitos do momento.

Como os alunos estrangeiros não utilizam livros-didáticos em que esteja o conteúdo previamente sistematizado, os professores-estagiários precisam preparar, além do roteiro de atividades que serve de guia para executar sua aula, também folhas de atividades para cada aula e materiais extras como imagens, vídeos, áudios etc. A execução dessas tarefas é acompanhada em três momentos específicos: antes da aula e, portanto, durante o processo de elaboração, durante a aula para observação dos pares e depois da aula para discussão e revisão dos procedimentos e materiais. 
Os procedimentos aqui descritos fazem parte das discussões mais recorrentes sobre a temática deste artigo. Diferentes autores (cf. PESSOA, 2009, p. 53, FABRI; RANGEL; BARIN, 2010, p. 3 e FISCARELLI, 2007, p. 4) assumem que a reflexões sobre materiais didáticos abordam questões como "análise de materiais existentes no mercado", "uso ou falta de uso de livro didático nas aulas", "elaboração de materiais didáticos complementares a livros didáticos adotados" e a "opção de não adotar, mas elaborar os próprios materiais didáticos". Em textos sobre Educação à Distância pode-se encontrar ainda a articulação entre uma espécie de plano de aula (CARDOSO; SILVA, 2008, p. 7) e a elaboração de material didático, geralmente, pensados e propostos em equipe. A adoção do trabalho em equipe, contudo, não é um privilégio da Educação à Distância, mas interessa aqui a maneira como o resgata para fins didáticos.

Sobre as dificuldades de professores para a elaboração de materiais didáticos, algumas crenças parecem recorrentes e acabam por sustentar certa resistência ao planejamento e à produção de materiais de forma coerente com a proposta de ensino em que o professor estiver inserido. Dentre essas, podem ser citadas as de que: (1) saber o conteúdo é suficiente para ministrar aulas; (2) planejar é tarefa para iniciante; (3) materiais didáticos e manuais já constituem as aulas em si (cf. CASTRO; TUCUNDUVA; ARNS, 2008, p. 56). Esta última ideia traz uma concepção equivocada de planejamento de aula diretamente associada ao tema deste artigo, que trata de articular planejamento de aula e elaboração de material didático, entendendo-os como elemento complementar e facilitador da aprendizagem.

A propósito do conceito de materiais didáticos, Fiscarelli (2007) entende tratar-se de

(...) todo ou qualquer material que o professor possa utilizar em sala de aula; desde os mais simples como o giz, a lousa, o livro didático, os textos impressos, até os materiais mais sofisticados e modernos. (FISCARELLI, 2007, p. 1).

Material didático, portanto, abarca todo tipo de objetos que atuam como instrumentos facilitadores do processo de ensino-aprendizagem nas aulas. Essa concepção adequa-se à abordagem de trabalho do NUPPLES/UERJ, uma vez que em suas aulas recorrem-se a todo tipo de material, especialmente os autênticos, incluindo-se objetos escolares, peças de jogos, imagens projetadas e em papel, livros de diferentes gêneros (romances, quadrinhos etc.), jornais, folhas de exercícios entre outros. Assim, muitos materiais são trazidos da realidade extraclasse e adquirem funcionalidade didático-pedagógica.

O uso e a elaboração desses materiais em um ambiente de aprendizagem formal não implicam abandono do conteúdo e de sua sistematização. Busca-se, na verdade, dar aos exercícios habituais o máximo de proximidade com a realidade de uso da língua, alvo da aprendizagem. Nesse contexto, propõe-se integrar o exercício 
a atividades dinâmicas e comunicativamente produtivas, ultrapassando a mera sistematização e a transformando em uma experiência mais significativa.

Acredita-se, desta forma, promover uma aprendizagem comunicativa e prazerosa que, ao mesmo tempo, articula treino e reflexão sobre os conteúdos dados, resgatando ao máximo o contato direto com as coisas (CHAGAS, 1979, p. 23). Com base nessa visão, atividades não são consideradas o mesmo que exercícios. Os materiais didáticos produzidos, no âmbito do Projeto, irão se referir a exercícios que funcionam, por princípio, dentro de atividades específicas.

De fato, para Cerqueira (2010, p. 132), atividade é "como algo que ultrapassa a visão imediatista da sala de aula, refletindo-se na formação dos sujeitos, de uma forma mais ampla". Já o exercício:

...estaria para o reducionismo do processo de ensino e aprendizagem, ou seja, estaria voltado para a prática em que se tem, de antemão, o propósito de se alcançar um objetivo mais imediato, não havendo, necessariamente, um comprometimento com a formação para além do espaço da sala de aula, mas a predominância do treinamento do que é ensinado. (CERQUEIRA, 2010, p. 132).

Em um primeiro momento pode-se ter a ilusão que a atividade corresponda tão somente à aplicação de certa dimensão lúdica à execução de tarefas em sala de aula. Entretanto, em um segundo momento, ao analisar de forma ampla os planos de aula e as folhas de exercícios, verifica-se que ambos são indissociáveis.

\section{Procedimentos metodológicos}

Atividades e exercícios ocorrem ao mesmo tempo e de forma integrada nas aulas de PL2E. O momento da atividade engloba de tal maneira o exercício que o material didático elaborado necessita não só "testar" o que o aluno aprendeu, mas se consegue aplicar o conteúdo aprendido sem se prender a estruturas pré-fabricadas. Resolver questões de exercícios, ao mesmo tempo em que vive experiências de interferência linguística real (dos colegas, professor e contextos reais) desenvolve mais substancialmente a proficiência na língua-alvo. Por isso, os materiais didáticos produzidos devem conter ordenados desafios a serem resolvidos com base em habilidades e conhecimentos desenvolvidos em determinada aula.

Entendendo-se que a elaboração de materiais didáticos se relaciona intrinsecamente à elaboração do plano de aula (roteiro de atividades logicamente sequenciadas), a equipe obedece aos seguintes passos cujo processo de execução é fonte para coleta de dados sobre a relação formação de professores e produção de materiais didáticos: (1) verificar e considerar os conteúdos gramaticais e os temas culturais; (2) elaborar uma sequência lógica de atividades com tempo de execução previsto, conciliando os conteúdos gramaticais com os temas culturais; (3) selecionar materiais autênticos (TV, publicidade, música, literatura etc.) que forem 
úteis para a realização das atividades descritas no roteiro; (4) incluir os materiais autênticos e criar outros com vistas a dar substrato linguístico e cultural às atividades propostas e promover as quatro habilidades linguísticas mínimas de acordo com os níveis dos alunos.

Como dito anteriormente, o acompanhamento e a supervisão do processo aqui descrito permite o levantamento de dados sobre a qualidade dos materiais didáticos e suas relações com as dificuldades e necessidades dos professores em formação. Para efeitos da pesquisa que ora se apresenta, foram coletados dados a partir da análise de quarenta (40) planos de aula e dos respectivos exercícios/atividades propostos e materiais didáticos em geral. Tomaram-se vinte (20) planos de dois estagiários diferentes, níveis $A 1$ e $A 2$, ambos no início do processo de formação e buscou-se: (1) identificar nesses planos os desafios desses estagiários para elaborar materiais didáticos para suas aulas; (2) relacionar os materiais produzidos e os planos de aula.

Para tanto, criaram-se categorias de análise a partir de três das dificuldades mais recorrentes na articulação dos materiais didáticos com os planos de aula, a saber, (1) a de equilibrar a apresentação do conteúdo linguístico-gramatical e do conteúdo cultural; (2) a de observar as especificidades e necessidades do públicoalvo (alunos estrangeiros) em relação ao nível de dificuldade dos exercícios/atividades; (3) a de tomar decisões apropriadas quando da escolha de materiais autênticos, seus gêneros e sua inserção na estrutura das atividades.

\section{Análise dos dados}

Antes de analisar os materiais didáticos elaborados pelos professores-estagiários a partir das dificuldades mencionadas, analisou-se a natureza desses materiais, para em seguida verificar à qual espécie cada nível priorizava.

Considerando-se materiais autênticos como aqueles extraclasse elaborados para auxiliar na execução das atividades e para facilitar a aprendizagem pelo contato direto com as coisas (CHAGAS, 1979, p. 23), registrou-se o levantamento de materiais que compunham as atividades dos planos: alimentos, cartões etc. Quanto aos materiais elaborados para aula, fez-se o levantamento daqueles que sofreram alguma adaptação em sua estrutura, como um texto incompleto e retirado de seu suporte original para a folha de exercícios. Observou-se entre os níveis A1 e A2, nos 40 planos de aula, se os professores usam em suas aulas mais materiais autênticos, mais materiais elaborados para suas aulas ou se articulam ambos os tipos. 


\section{SILID IV

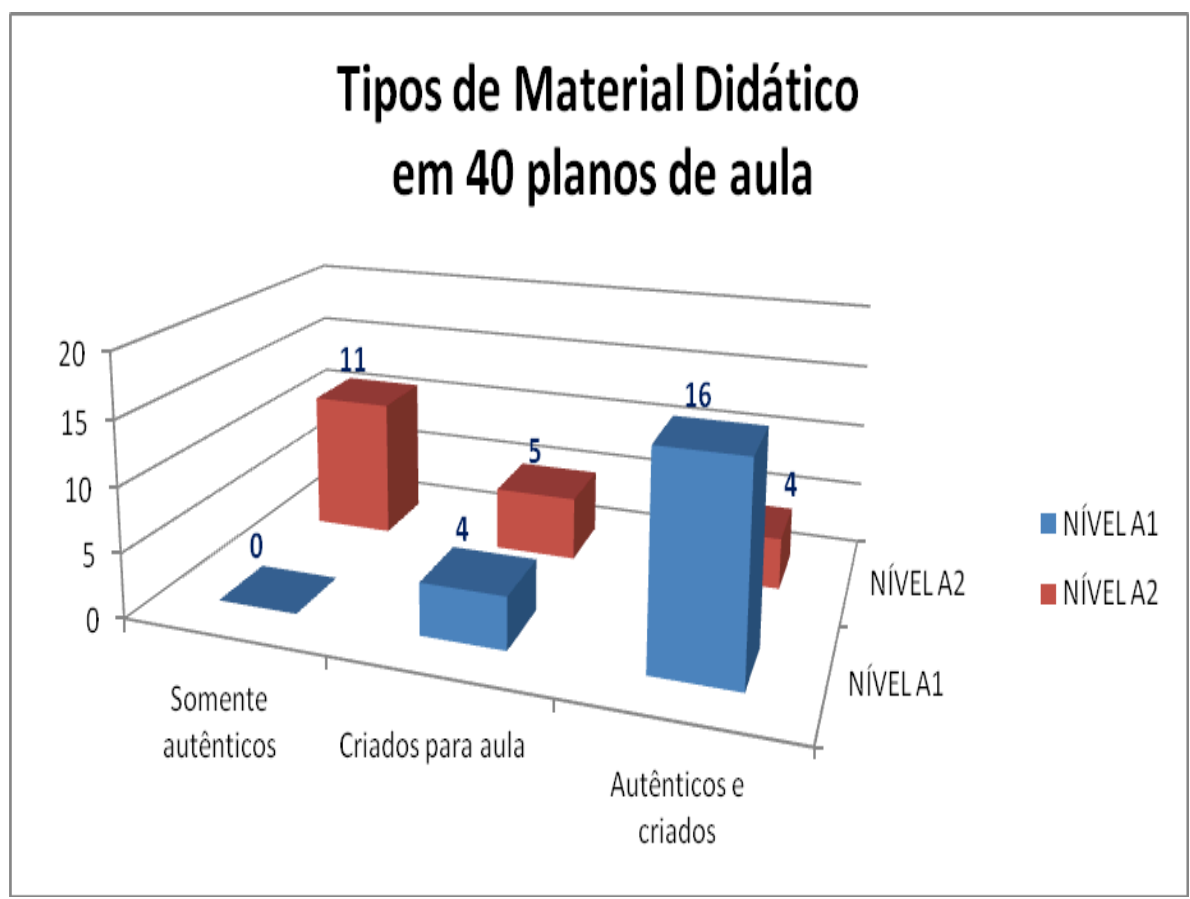

Gráfico 1: Tipos de Material Didático.

O Nível A1 demonstrou conciliar mais materiais autênticos e elaborados do que o Nível A2. Esse critério de análise leva a crer que o Nível A1 tem mais necessidade de adaptar os materiais para o nível de dificuldade do seu público-alvo, uma vez que seu conhecimento linguístico-cultural é insipiente para que as aulas se sustentem apenas com materiais autênticos.

Passando para as dificuldades dos professores-estagiários em articular os materiais didáticos com os planos de aula, analisou-se a maneira como os materiais didáticos estão inseridos nos planos de aula, se seguem o encadeamento lógico das atividades registradas nos planos ou se estão inseridos sem uma função claramente registrada. Foram divididos, então, em "inseridos logicamente" e "inseridos isoladamente". 


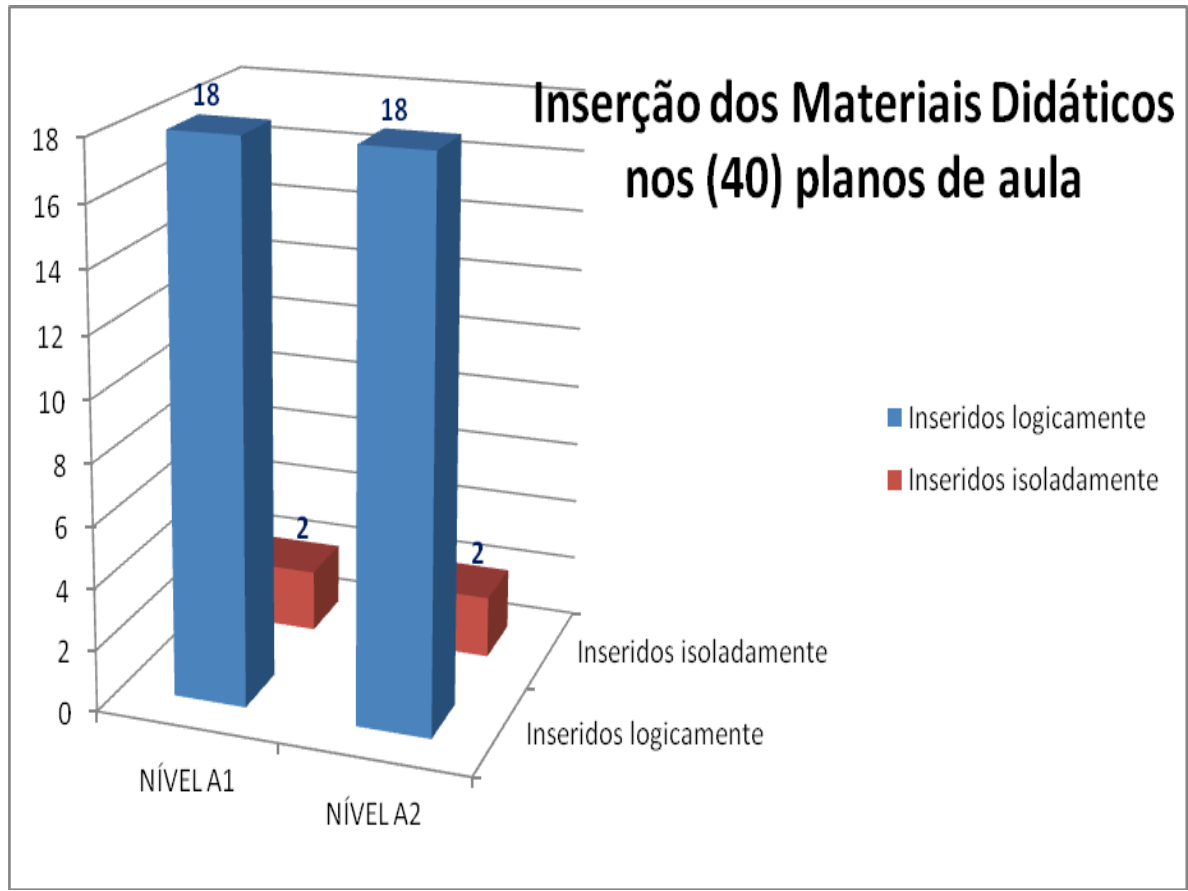

Gráfico 2: Inserção dos Materiais Didáticos nos planos de aula.

Ambos os níveis demonstraram conseguir articular os materiais didáticos às atividades propostas nos planos de aula, o que se considera fruto do trabalho em equipe, já que tanto os planos quanto os materiais analisados haviam passado por uma supervisão.

O passo seguinte foi quanto à dificuldade dos professores-estagiários em equilibrar conteúdo linguístico-gramatical e conteúdo cultural, analisando-se, portanto, em que medida os materiais atendiam a esse equilíbrio, se atendiam. Para isso, o gráfico a seguir é composto por dois, contribuindo para a comparação e o balanceamento entre ambos conteúdos. 


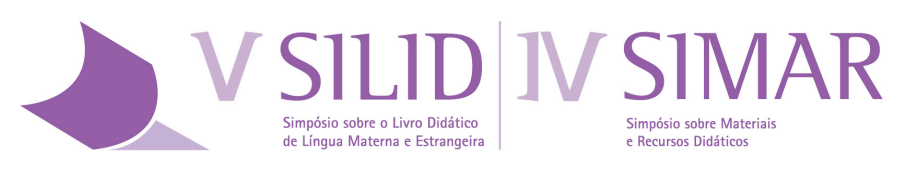

PUC-Rio - Dias 28, 29 e 30 de julho de 2015

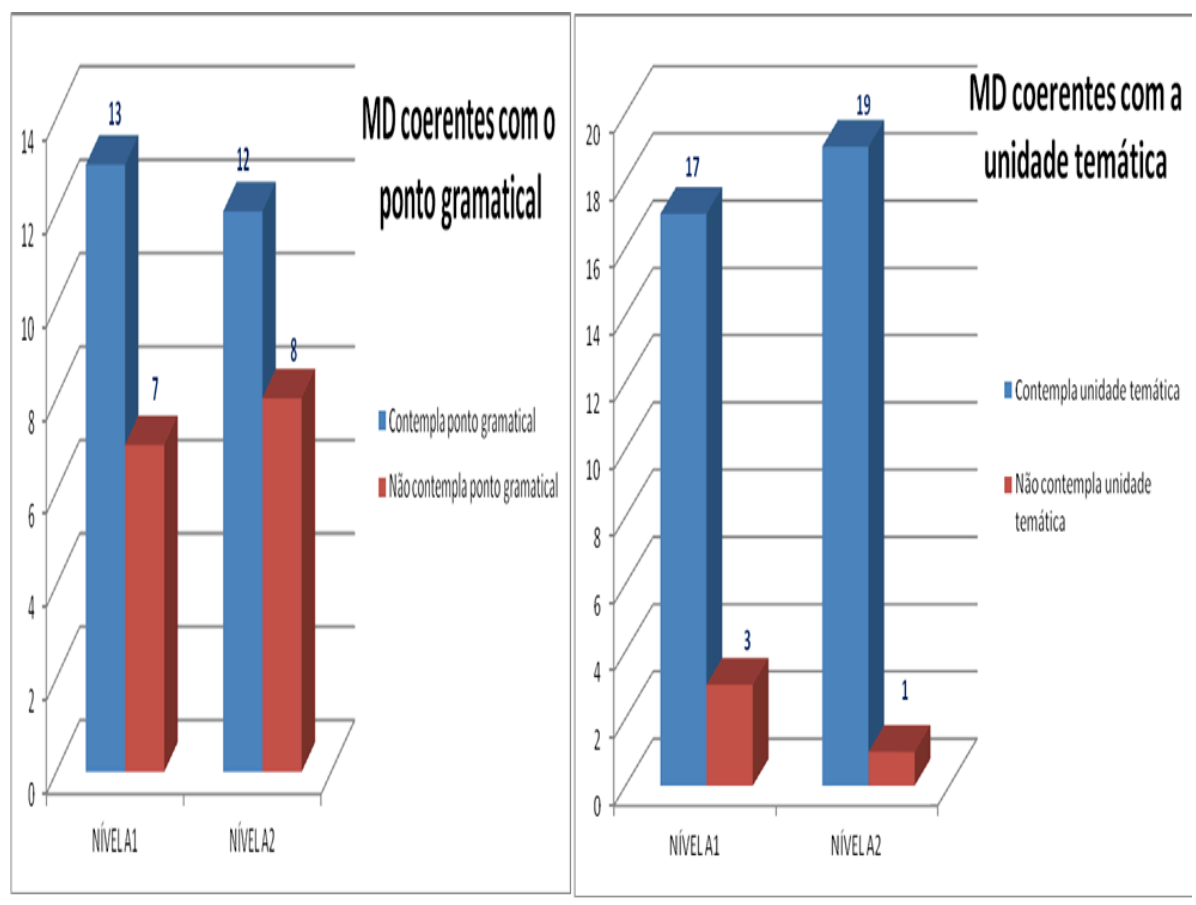

Gráficos 3 e 4: Materiais Didáticos coerentes com os conteúdos linguístico-gramatical e cultural.

Os dois níveis na maioria das vezes buscaram contemplar os pontos gramaticais e as unidades temáticas na elaboração dos materiais, contudo, a quantidade de materiais que não contemplaram os pontos gramaticais é elevada em comparação aos que não contemplaram as unidades temáticas. Assim, há uma preocupação maior em adequar os materiais didáticos às unidades temáticas do que aos pontos gramaticais, o que pode ser explicado por esses professores ainda estarem em formação inicial e, portanto, terem pouco domínio do conteúdo gramatical e lhes faltar também a experiência para equilibrar o conteúdo e o tema.

Em relação à dificuldade dos professores-estagiários em adequar os materiais didáticos às especificidades e necessidades do público-alvo, já foram vistos que tipo de material cada nível requer e o quanto os conteúdos de cada nível dificultam o equilíbrio entre os assuntos gramatical e temático no planejamento da aula. No entanto, uma vez que os materiais são elaborados e selecionados de acordo com as atividades do plano de aula, os materiais didáticos também precisaram ser analisados em relação aos comandos dos exercícios. Eles poderiam estar explicitados nas folhas de exercícios ou registrados apenas nas atividades dos planos de aula, indicando, neste último caso, que os comandos seriam dados oralmente durante a execução da tarefa em aula. 


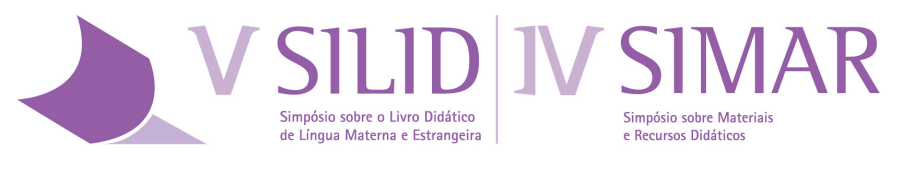

PUC-Rio - Dias 28, 29 e 30 de julho de 2015

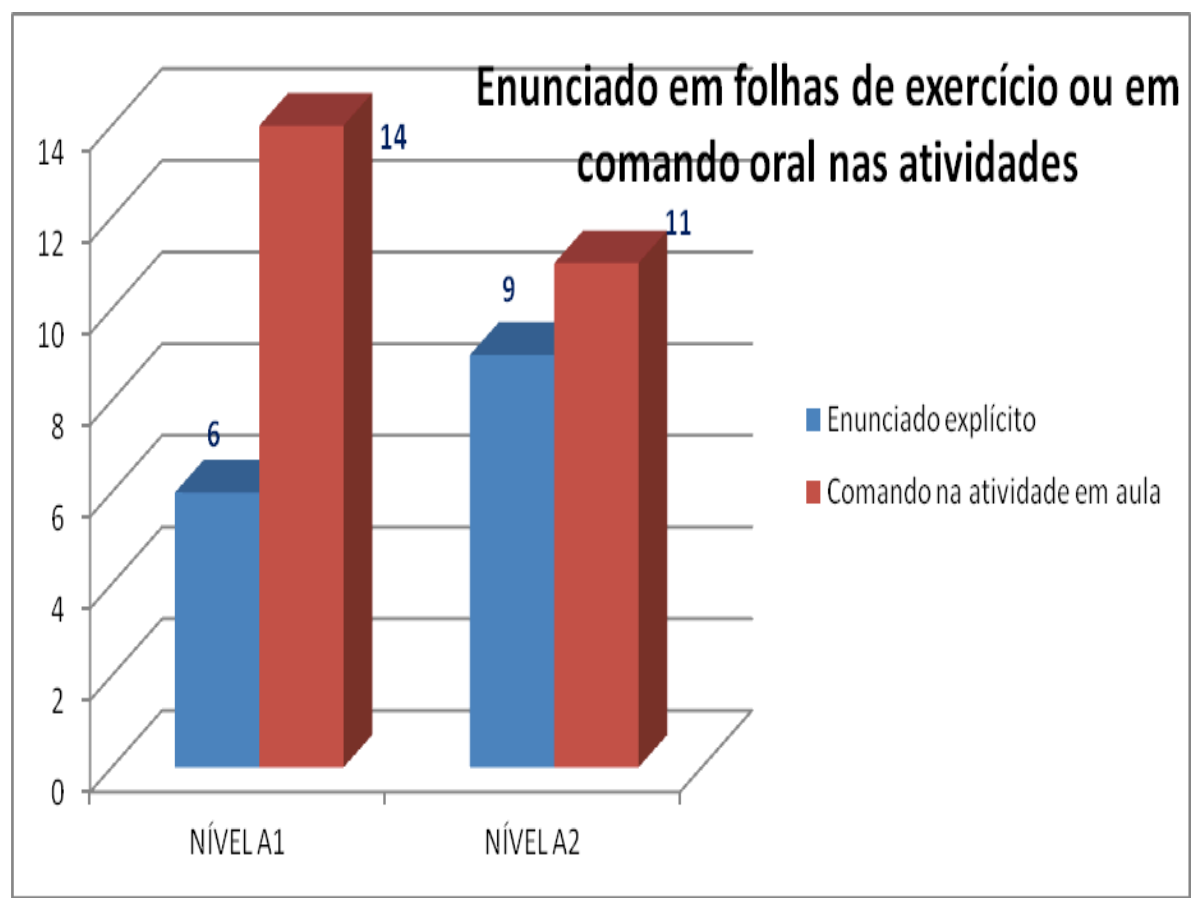

Gráfico 5: Comandos dos exercícios dos Materiais Didáticos.

O Nível A1 teve uma alta carga de comando oral dos exercícios nas atividades em comparação com a carga de enunciados explícitos nos próprios materiais. Já o Nível A2 conciliou mais comandos orais e enunciados explícitos. Nota-se, então, que o conhecimento linguístico-cultural dos alunos no Nível A1 implica na necessidade de integrar os exercícios da folha às atividades do plano, enquanto no Nível A2 o conhecimento linguístico-cultural dos alunos já lhes habilita a associar o enunciado da folha ao comando oral da atividade. Disso se pode concluir que o professor buscou, mais uma vez, adequar os materiais às especificidades do nível do seu público-alvo.

Para concluir, fez-se uma análise geral de todos os materiais didáticos, utilizando-se todos os critérios mencionados, desde os tipos de materiais até os comandos dos exercícios. 


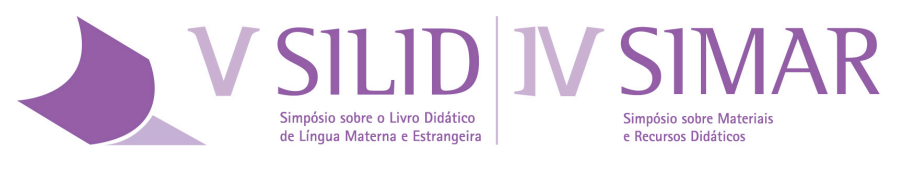

PUC-Rio - Dias 28, 29 e 30 de julho de 2015

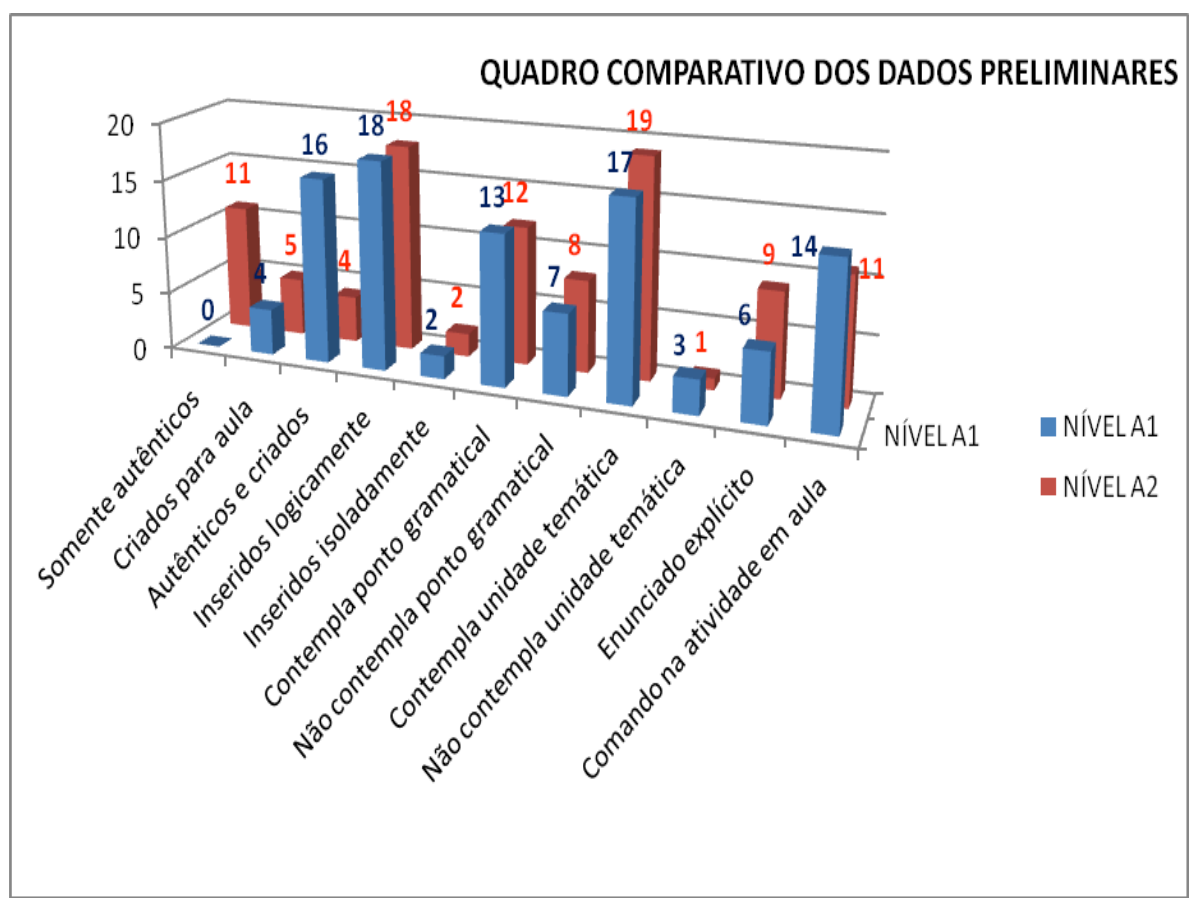

Gráfico 6: Quadro comparativo dos dados preliminares.

Por um lado, há uma predominância em se articular os materiais didáticos aos planos de aula e de adequá-los às unidades temáticas, resultados da supervisão que orienta os professores a uma metodologia comunicativa. Por outro lado, existe a dificuldade de se equilibrar o conteúdo gramatical e a unidade temática quando da elaboração dos materiais. Ressalta-se que a orientação é o que conduz a articulação entre materiais didáticos e planos de aula.

\section{Considerações finais}

Acreditava-se que os resultados apontariam para dificuldades que no fundo refletem crenças arraigadas sobre o ensino-aprendizagem como as que sustentam que aulas devem priorizar conteúdos gramaticais em detrimento de conteúdos culturais e suas mútuas relações. Por isso, mesmo, muitos materiais didáticos são propostos, desconsiderando a heterogeneidade das turmas e das estratégias de aprendizagem que melhor funcionam para cada grupo como se as classificações por níveis de conhecimento fossem verdades absolutas sobre os indivíduos-aprendizes.

Contudo, os resultados apontaram para dificuldades em trabalhar o conteúdo gramatical e conciliá-lo com o conteúdo temático-cultural. É comum que, ao chegar ao Projeto NUPPLES/UERJ, os professores-estagiários preocupem-se mais com o componente a ser ensinado e menos com o público-alvo, uma vez que desconhecem suas necessidades e dificuldades e inferindo que sejam as mesmas do público de falantes nativos do português. Durante sua participação no Projeto, uma das primeiras crenças abandonadas é a de que dar aula de PL2E não é como dar 
aula de português língua materna (PLM) porque o público-alvo não é o mesmo e, por isso, requer outra didática. Como ainda estão em fase de formação inicial, os professores tendem à radicalização, levando em conta mais o público-alvo do que o conteúdo linguístico-gramatical a ser ensinado. Além disso, costumam ter um conhecimento gramatical pouco profícuo para relacioná-lo a fenômenos linguísticos e culturais de forma a satisfazer as necessidades e as dificuldades do público estrangeiro. Isso se dá muitas vezes devido a um currículo de Letras "engessado", que não contempla questões relacionadas ao ensino de PL2E. Nesse sentido, ao levar mais em conta o público-alvo e, por terem conhecimento gramatical ainda insipiente, acabam trabalhando mais o conteúdo temático do que o gramatical, contrariando o esperado.

No que diz respeito ao domínio do conteúdo e sua aplicabilidade, há que se pensar no papel dos cursos de formação e de como esses contribuem para que os professores consigam eficiência em suas práticas didáticas. É que os conteúdos gramaticais parecem ser dominados superficialmente apesar do uso de um discurso metalinguístico constante pelos professores. O conhecimento metalinguístico parece dissociado de sua possível aplicabilidade, o que faz com que materiais didáticos, como os de PL2E, por exemplo, tendam a estruturas não reais e descontextualizadas.

Este texto, ao apresentar as relações entre formação de professores e produção de materiais didáticos em contextos específicos, buscou sustentar que um dos papéis da formação de professores é evitar que essa se torne uma realidade na prática de profissionais "já formados".

\section{Referências Bibliográficas}

CARDOSO, M. Y. N. P.; SILVA, A. C. C. Metodologia para construção de materiais didáticos na EaD: do plano de ensino ao roteiro de tutoria. In: Associação Brasileira de Educação a Distância. Disponível em: <http://www.abed.org.br/congresso2008/tc/1152008220039.pdf>. Acesso em: 18 jul. 2015.

CASTRO, P. A. P. P.; TUCUNDUVA, C. C; ARNS, E. M. A importância do planejamento das aulas para organização do trabalho do professor em sua prática docente. Athena - Revista Científica de Educação, v. 10, n. ${ }^{0} 10$, jan./jun. 2008.

CERQUEIRA, M. S. Atividade versus exercício: concepções teóricas e a prática da produção textual no ensino de língua portuguesa. Revista Trabalhos em Linguística Aplicada, v. 49(1), p. 129-143, jan./jun. 2010. 
FABRI, A. S.; RANGEL, E.; BARIN, N. R. Construção de material didático para o ensino de português para estrangeiros. In: XVI Jornada Nacional da Educação. Disponível em: <http://jne.unifra.br/artigos/4931.pdf>. Acesso em: 18 jul. 2015.

FERREIRA, S. R. A docência na EaD. A docência na EaD. In: Anais do $\boldsymbol{V}$ Seminário Internacional de Educação a Distância. Disponível em <https://www.ufmg.br/ead/seminario/anais/pdf/Anais_V_SIEAD.pdf>. Acesso em: 18 jul. 2015.

FISCARELLI, R. B. O. Material didático e prática docente. In: Revista IberoAmericana de Estudos em Educação. Disponível em: <http://seer.fclar.unesp.br/iberoamericana/article/view/454>. Acesso em: 18 jul. 2015.

OliveIRA, E. A; CERDAS, L.; MAURO, R. A experiência de EaD do Centro Universitário de Araraquara/SP: o trabalho do professor-tutor na interação dos processos de ensino e aprendizagem. In: Anais do $\boldsymbol{V}$ Seminário Internacional de Educação a Distância. Disponível em: <https://www.ufmg.br/ead/seminário/anais/pdf /Anais_V_SIEAD.pdf>. Acesso em: 18 jul. 2015.

PESSOA, R. R. O livro didático na perspectiva da formação de professores. Revista Trabalhos em Linguística Aplicada, v. 48(1), p. 53-69, jan./jun. 2009.

RIBEIRO, A. A. Ensinar aprendendo e aprender ensinando: a formação docente como eixo norteador da área de Português Língua Não Materna (PLNM) na UERJ. In: MEYER, R.M.B; ALBUQUERQUE, A.F.S. Português: uma língua internacional. Rio de Janeiro: Editora da PUC, 2015. 